Open Access

\title{
Lending credence: motivation, trust, and organic certification
}

Steve Hollande

Correspondence:

steve.holland@luther.edu Luther College, 700 College Drive,

Decorah, IA 52101, USA

\begin{abstract}
The information asymmetries inherent in credence goods have typically led economists to conclude these markets require well-defined quality standards and third-party verification that producers are meeting those standards. Nonetheless, many producers of credence goods appear to be opting out of certification. Why? This paper builds in previous research and develops a theoretical framework to think about how producers' motivation and relationships with consumers affect the necessity and effectiveness of certification. I find the degree to which a consumer trusts the producer of a credence good and the certification standard that governs it and the degree to which the producer is motivated to produce a good of a certain quality both have important effects on certification-based regulation.
\end{abstract}

Keywords: Credence goods, Organic food, Certification, Agriculture, Trust, Intrinsic motivation

\section{Background}

Various forms of regulation are often used to improve the performance of markets when relevant information is lacking. A good example is markets for "credence goods" or goods with characteristics that are difficult or impossible for consumers to observe even after purchase and use (Darby and Karni 1973). Credence goods included goods such as organic food, fair trade goods, energy-efficient appliances, automobile repairs, and medical services. The information asymmetries inherent in credence goods have typically led economists to conclude these markets require well-defined quality standards and third-party verification that producers are meeting those standards.

Nonetheless, many producers of credence goods appear to be opting out of certification. This suggests the information problems certification is intended to solve are often being dealt with effectively by market participants. How? Previous research makes clear that producers and consumers of organic food, to use one example, draw on a complex set of motives and employ significant trust when deciding whether to seek organic certification or purchase certified organic food. Might these other motives help explain the puzzling use of certification standards?

The goal of this paper is to model how producers' motives and consumers' trust (in both producers' claims and certification standards) affect the production of credence goods and the decision to certify them. There have been few attempts to develop a

(C) 2016 The Author(s). Open Access This article is distributed under the terms of the Creative Commons Attribution 4.0 International License (http://creativecommons.org/licenses/by/4.0/), which permits unrestricted use, distribution, and reproduction in any medium, provided you give appropriate credit to the original author(s) and the source, provide a link to the Creative Commons license, and indicate if changes were made. 
theoretical framework to think about how producers' motivation and relationships with consumers affect certification, and this paper begins to fill that gap. I find the degree to which a consumer trusts the producer of a credence good and the certification standard that governs it and the degree to which the producer is motivated to produce a good of a certain quality both have important effects on certification-based regulation.

\section{Credence goods}

Darby and Karni (1973) observed that credence goods "arise whenever a good is utilized either in combination with other goods or uncertain properties to produce measurable output or in a production process in which output, at least in a subjective sense, is stochastic, or where both occur." In addition, the quality of the output "cannot be evaluated in normal use" and "the assessment of [the good's] value requires additional costly information."

Credence goods, by definition, involve an information asymmetry that creates tricky decisions for both the consumer and the producer. Caswell and Mojduszka (1996) succinctly summarize the problem:

Economic models of quality hit a dead end when they come to discussion of credence attributes or goods because information is so imperfect that these markets for quality simply do not function well.

The reason the markets for credence goods do not function well is because there are strong incentives for fraud (Darby and Karni 1973; Emons 1997; Dulleck and Kerschbamer 2006). In the context of organic food, for example, ${ }^{1}$ there is likely to be a price premium for organic at the same time that conventional production costs are lower. A producer who grows food conventionally could falsely claim organic status, enjoy the lower production costs, and still collect the organic price premium. Producers, then, have a dominant strategy to claim organic status whether or not the food was actually produced according to organic standards. Often, the benefits of short-run opportunistic behavior are overshadowed by the long-run costs of developing a bad reputation. However, reputation alone cannot solve the credence good problem because consumers will not usually know if they have been cheated (Caswell and Mojduszka 1996; McCluskey 2000; Ward et al. 2004).

Recognizing producers' incentives to mislead, and faced with an inability to verify producer claims, consumers should be unwilling to pay a price premium for organic food. As Akerlof (1970) noted, in a market where the quality of goods can be misrepresented, "[t]he presence of people in the market who are willing to offer inferior goods tends to drive the market out of existence." In short, consumers have a problem determining the quality of credence goods, producers have a problem convincing consumers that the goods have credence characteristics and are priced appropriately, and as a result, there appears to be a substantial risk that markets will fail and exchange will be thwarted.

\section{Regulation of credence goods}

Therefore, theory suggests that institutions such as third-party standards and certification, liability regimes, and verifiability rules must be used to solve the credence 
good problem and allow a market for items such as organic food to exist (Caswell and Padberg 1992; McCluskey 2000; Giannakas 2002).

As McCluskey (2000) shows, when a third party can monitor a producer's organic practices less expensively than a consumer could, and when the probability is sufficiently high that the monitoring is accurate, then, and only then, can a market for organic food exist. Giannakas (2002) claims, "In fact, labeling based on third-party certification is the only feasible alternative to circumventing supply-side failures of markets for organic food since, in its absence, organic food suppliers are not capable of signaling the nature of their product." The basic story that emerges from the academic and trade literature is that producers of credence goods will seek certification if the benefits of regulation exceed the costs (Golan et al. 2001; McCluskey 2000). In the case of organic food, a producer should only seek thirdparty certification if the organic price premium justifies the cost of certification and compliance.

This argument is compelling but fails to fully explain why it is common for sellers to produce a good with credence qualities without employing third-party certification. For example, there are many farmers who grow food using organic practices but eschew organic certification. While accurate statistics are difficult to find, some studies suggest that close to half of organic producers may be noncertified. In a study of organic producers in California, Guthman (2001) noted finding that over half of organic producers do not bother to seek certification. Similarly, a study of organic farming in Texas by Constance et al. (2008) found that about $40 \%$ of organic farmers surveyed were not certified. In developing nations, the proportion of farmers who grow organically but do not become certified may be much higher than that in the USA (Cáceres 2005).

Theory does not do a very good job explaining why producers would include expensive credence qualities in their goods but not seek the price premium that usually comes with certification. Differences in the costs of producing credence qualities can only partially explain this behavior. The apparent proliferation of noncertified credence goods can only be understood by recognizing that producers' decisions about how to produce and whether to seek certification are more complicated than merely comparing revenue and costs.

Empirical studies of organic farms have found there to be many factors, beyond profit, that motivate producers to add credence qualities to their goods (see Kallas et al. (2009) for an excellent summary). These "non-economic" factors include environmental concerns, health risks, soil quality, demographics, lifestyle, and ideology (Hall and Mogyorody 2001; Kallas et al. 2009). Further complicating things, many producers who choose to use some organic methods may have a variety of reasons, in addition to certification costs and potential price premiums, which drive their decision whether to become certified. These include relationships and trust with consumers (Constance et al. 2008), red tape and paperwork (Cáceres 2005), and community involvement and civic engagement (Munasib and Jordan 2011).

In short, the empirical literature has many excellent studies that demonstrate producers consider more than profit when deciding whether to include credence qualities and seek certification. The literature also shows that certification is not 
the only way market participants overcome the asymmetric information problems posed by credence goods. These studies point to the need for a theoretic framework to think about the mechanism by which producer motives alter the decision to produce and certify credence goods. This paper is a first attempt at such a framework.

The model finds the standard result-that certification is optimal for a producer whenever the difference in price between a certified and non-certified good is large enough to cover the cost of certification-to be true only in the limited case when the consumer trusts the certification regime but does not trust the producer. However, when the consumer trusts the producer and/or does not trust the certification standards, then a producer, even one who is producing a good with credence qualities, is likely to seek certification in a much narrower set of circumstances.

\section{Methods}

A producer must answer two questions: (1) will the producer's goods contain credence qualities? and (2) will the producer seek certification? The producer of a credence good, like other producers, wants to maximize net benefits. In this model, the producer's objective function is comprised of (1) the price received for the good, less (2) the cost of production and certification, plus (3) the "motivation benefit" of production, which is roughly an extrinsic or intrinsic reward from producing a good with certain qualities. The producer maximizes net benefit by choosing the quality of the good and whether or not to seek third-party certification.

In this model, the agents measure the quality of a good $(Q)$ on a scale from 0 to 1 , where 0 represents a good with no credence qualities. A "lower" quality good, then, simply contains few credence characteristics and does not imply that it is inferior. In fact, an important feature of this model is that agents might very well prefer a good of lower quality. Similarly, the certification standard $(S)$ is also defined by some level of quality on the range $[0,1]$. That is, the certification standard is met when $Q \geq S$ but not when $Q<S$.

Since the producer's choices are complicated by complex interactions between the three components of the objective function, some discussion of each is worthwhile.

\section{Expected revenue}

A central issue for the producer of a credence good is whether the price will reflect the good's credence qualities. In this model, there is a single consumer and the price of the credence good is equal to the consumer's willingness to pay for it, denoted by

$$
P=\left\{\begin{array}{c}
P_{c} \text { if the producer certifies } \\
P_{n} \text { if the producer does not certify, }
\end{array}\right.
$$

So how much should a consumer be willing to pay?

Begin with the simpler case of a good that is not certified. Here, certification provides no information and the consumer cannot determine the actual quality of 
the good. The consumer's willingness to pay, then, reflects an expectation about quality, which is described by a probability density function, $f(Q)$. The different ways in which this expectation can be formed are central to my conclusions and will be discussed in a later section. Further, the value the consumer places on goods with various levels of quality is described by a value function, $V(Q)$, which is single-peaked and maximized at the consumer's ideal level of quality, $Q^{*}$ (illustrated by Fig. 1). Therefore, the expected value of a good sold by a non-certified producer (and, consequently, the consumer's willingness to pay for it) is

$$
E\left[V_{n}\right]=\int_{0}^{1} V(Q) f(Q) d Q=P_{n}
$$

The consumer's willingness to pay for a certified good is slightly different because certification provides additional information about the good's true quality. I assume a good of higher quality than the certification standard $(Q \geq S)$ is certain to be certified and will receive whatever price certification warrants. ${ }^{2}$ However, I also assume the certification process is not foolproof. A producer whose good falls below the certification standard has some positive probability that a certification request will be granted. The certifier can be tricked, but doing so becomes more difficult as the true quality diverges from the standard. Formally, the probability that a good will become certified is denoted by the function $\theta(Q, S)$ where $\theta$ is increasing but less than 1 as $Q$ approaches $S$ and then equal to 1 for all $Q \geq S$.

The consumer of a certified good, therefore, forms a conditional expectation of the value of the good (i.e., the expected value of the good, given that certification has been awarded). Using Bayes' theorem, the expected value of a certified good is

$$
E\left[V_{c}\right]=\int_{0}^{1} V(Q) f(Q) \frac{\theta(Q, S)}{\int_{0}^{1} f(Q) \theta(Q, S) d Q} d Q=P_{c}
$$

A producer who seeks certification, then, will have expected revenue equal to $(1-\theta) P_{n}+\theta P_{c}$.

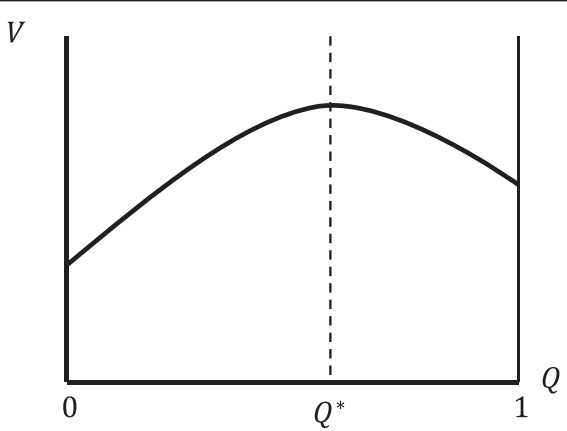

Fig. 1 Consumer's value function. Illustrates the consumer's value function, $V(Q)$. In this case, the value function is maximized at the credence quality level $Q^{*}$ and the value the consumer places on the good falls as the quality deviates from $Q^{*}$ 
Costs

The producer's total costs are the sum of the cost of production and the cost of complying with the certification requirements. The cost of production, $\gamma(Q)$, is a function of the quality of the good and has the normal characteristics of a cost function, including positive marginal costs.

The cost of certification, $\delta(Q, S)$, increases with the certification standard $(S)$. As the standard demands higher quality, the costs of proving that higher quality (which are different than the costs of producing a higher quality good) increase. The cost of certification is also a function of the quality of the good (Q) because when the product quality is below the certification standard, it forces a producer who wants certification to take costly action to "cover up" deviations from the standard. I assume the cover-up costs fall as quality gets closer to the standard, so that when quality meets or exceeds the certification standard, no cover-up costs are incurred and $\delta$ equals the out-of-pocket costs of obtaining certification, that is, the marginal certification costs for changes in quality are negative for $Q<S$ and go to 0 as the producer's production quality equals and then exceeds the certification standard.

\section{Motivation benefit}

This model of credence goods is unique because it includes a motivation benefit. Producers are homogeneous with respect to the expected revenue and cost portions of the net benefit function, but there are many reasons one credence good producer might want to produce a different quality of good from another producer. The motivation benefit is an effort to capture that.

The motivation benefit could be interpreted as differences in the cost structure, such as when a farmer's land or soil conditions make it beneficial to reduce the amount of fertilizer used. The motivation benefit could also be interpreted as an "intrinsic benefit" (when the reward for an activity is the joy of the activity itself (Deci 1971)), such as the satisfaction a farmer might get from a belief that reducing chemical usage results in healthier food for his customers. Psychologists and economists have recognized the importance of intrinsic motivation and begun to try understanding how external interventions, such as regulation or certification, can either reinforce or undermine intrinsic motivation (Frey 1994). This paper is in that vein, although the motivation benefit in this model is intended to be flexible enough to capture both extrinsic and intrinsic benefits that distinguish one producer from another.

Formally, producers receive motivation benefits, represented by the function $M$, from the quality of their good. Producers have single-peaked preferences over quality (similar to the consumer's value function), so they have an opinion about the ideal product quality and get a lower motivation benefit as the actual quality moves away from that ideal (in either direction).

Combining the three components of the producer's net benefit function and utilizing Eqs. 1 and 2 results in

$$
\text { Net benefit }=\left[(1-\theta) P_{n}+\theta P_{c}\right]-(\gamma+\delta)+M
$$




\section{Results and discussion}

\section{How does certification affect product quality?}

Although we do not yet know the conditions under which a producer is likely to seek certification, this is nonetheless a good place to pause and explore how certification, assuming it is obtained, will affect the quality of a credence good. I do this by comparing the optimal quality of a certified good to the optimal quality of a non-certified good.

The producer chooses an optimal level of quality to maximize net benefit, but, due to differing prices and costs, there will be different optimal levels of quality for certified and non-certified goods. Using Eq. 3, the expected net benefit of certifying is

$$
\text { Net benefit of certifying }=\theta P_{c}+(1-\theta) P_{n}-\left(\gamma_{c}+\delta\right)+M_{c}
$$

where the subscript $c$ continues to denote the value of each function when a producer chooses to certify. A producer who does not seek certification incurs no certification $\operatorname{cost}(\delta=0)$ and is certain to receive the non-certified price $(\theta=0)$, so the net benefit of not certifying is

$$
\text { Net benefit of not certifying }=P_{n}-\gamma_{n}+M_{n} \text {. }
$$

The prices in both equations are treated as constants because the certification standard is taken as given and both prices depend on the consumer's perception of quality rather than the producer's choice of quality. Therefore, the first-order conditions for the certified and non-certified producer, respectively, are

$$
\frac{\partial M_{c}}{\partial Q}+\frac{\partial \theta}{\partial Q}\left(P_{c}-P_{n}\right)=\frac{\partial \gamma_{c}}{\partial Q}+\frac{\partial \delta}{\partial Q}, \text { and } \frac{\partial M_{n}}{\partial Q}=\frac{\partial \gamma_{n}}{\partial Q}
$$

These represent the familiar condition that marginal benefits (the left side) equal marginal costs (the right side).

It is important to compare the first-order conditions. The marginal benefits differ by the term $\frac{\partial \theta}{\partial Q}\left(P_{c}-P_{n}\right)$, which represents the marginal benefit that comes from increasing quality, improving the probability of being certified and, consequently, getting the certified price premium. Since this term is positive but decreasing toward 0 as the quality becomes equal to the certification standard (since $\theta=1$ when $Q=S$ ), the marginal benefits of increasing $Q$ for the certified and non-certified producers are the same for $Q \geq S$.

Similarly, the marginal costs differ by the term $\frac{\partial \delta}{\partial Q}$, the marginal cost of certification. This term is negative but increasing toward 0 because cover-up costs fall as the level of quality reaches the certification standard. Therefore, the marginal costs of increasing quality for certified and non-certified producers are also the same for $Q \geq S$. 
Figures 2 and 3 illustrate these points. In both graphs, the marginal costs for a non-certified producer $\left(\mathrm{MC}_{n}\right)$ contain only production costs and are therefore positive and rising. The marginal benefit for a non-certified producer $\left(\mathrm{MB}_{n}\right)$ consists of the marginal motivation benefit, which is positive for levels of quality below the producer's optimal level (denoted $\hat{Q}$ ), equal to 0 at the optimal, and negative beyond that due to the single-peaked nature of the motivation function. The non-certified producer chooses the optimal level of quality $\left(Q_{n}\right)$ that equates $M C_{n}$ and $\mathrm{MB}_{n}$. For the reasons explained in the previous paragraph, the certified producer's marginal benefit $\left(\mathrm{MB}_{c}\right)$ is higher than that of the non-certified producer when quality is below the certification standard. Similarly, the certified producer's marginal costs $\left(\mathrm{MC}_{c}\right)$ are lower than those of the non-certified producer for quality below the standard. The certified producer maximizes net benefits by choosing quality equal to $Q_{c}$.

This leads to the first conclusion. As shown in Fig. 2, when the producer's ideal level of quality is below the certification standard $(\hat{Q}<S)$, certification will cause the producer to increase the optimal level of quality (i.e., $Q_{c}>Q_{n}$ ). However, when the producer's ideal level of quality is considerably above the certification standard $(\hat{Q}>S)$, certification does not increase the producer's optimal level of quality $\left(Q_{c}=Q_{n}\right.$ as shown in Fig. 3). The intuition is that when a producer is inclined to produce with fewer credence qualities than is required by the certification standard, the risk of failing a certification inspection and the added cost of covering up deficiencies will cause a producer to increase quality. But when a producer is already motivated to produce a good with many credence qualities, a weaker certification standard will not change behavior.

\section{The zone of certification}

With this understanding of how certification affects quality, it is now possible to better understand the conditions that will cause producers to seek certification in the first place. To do this, it is necessary to compare the net benefit of certification (given the optimal level of quality, $Q_{c}$ ) to the net benefit of not certifying (given $\left.Q_{n}\right)$. Formally, certification is optimal when

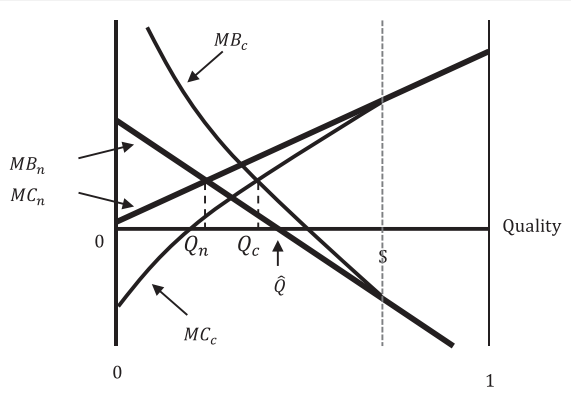

Fig. 2 Optimal quality when the certification standard is above the producer ideal. The optimal level of quality for the certified producer $\left(Q^{\top}\right)$ is above the optimal level of quality for the non-certified producer $\left(Q^{n}\right)$ when the certification standard $(S)$ is well above the producer's preferred level of quality $(\hat{Q})$ 


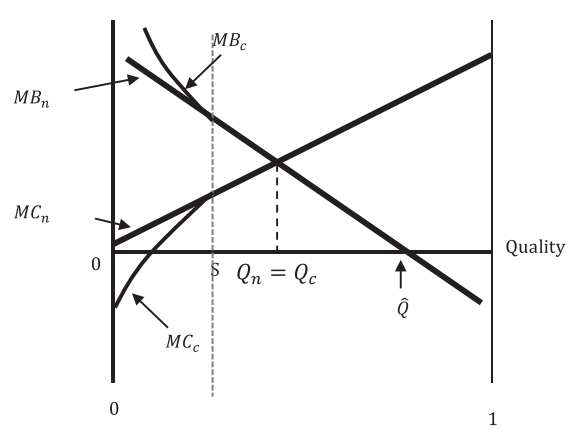

Fig. 3 Optimal quality when the certification standard is below the producer ideal. The optimal level of quality for the certified producer $\left(Q^{c}\right)$ is equal to the optimal level of quality for the non-certified producer $\left(Q^{n}\right)$ when the certification standard $(S)$ is well below the producer's preferred level of quality $(\hat{Q})$

$$
\left[\theta P_{c}+(1-\theta) P_{n}-\left(\gamma_{c}+\delta\right)+M_{c}\right]>\left[P_{n}-\gamma_{n}+M_{n}\right]
$$

The balance of this inequality depends significantly on the certification standard, which affects both price and costs, and the producer's ideal quality, which affects the motivation function. Therefore, the remainder of the paper is dedicated to deriving and discussing the "zone of certification," or the set of certification standards and producer ideals that would lead a producer to seek certification.

Obtaining analytical solutions and converting them into meaningful observations is difficult here. However, numerical solution methods are not difficult and yield illuminating results. In this case, reasonable parameters where chosen, distributions were constructed for the necessary functions, and MATLAB was used to solve for the zone of certification. Appendices 1 and 2 give more technical detail about these methods.

\section{The consumer's perception of quality}

A consumer cannot observe the quality of a credence good, so the consumer's perception of its quality depends, in large part, on whose claims can be believed. Therefore, the zone of certification also depends crucially on whom the consumer can believe. A consumer could trust the certification standards, for example. On the other hand, the consumer could trust the producer. Of course, a consumer could trust both the standards and the producer, or the consumer could trust neither. That gives us four general situations to consider:

\begin{tabular}{lll}
\hline The consumer... & trusts the producer's claims. & does not trust the producer's claims. \\
trusts the certification standards. & Trusting consumer & Typical consumer \\
does not trust the certification standards. & Relationship-based consumer & Skeptical consumer \\
\hline
\end{tabular}


The goal of this paper is not to explain how a consumer comes to trust various claims about a credence good's quality, although it is worth noting that a given consumer's type might depend on the setting (e.g., one could be "trusting" at a farmers' market but "typical" in a grocery store). Instead, the purpose is to point out the different beliefs and then explore the implications of each.

In the following sections, I will consider each of the four possibilities and conclude that both the consumer's perception of quality and the producer's motivation are critical to understanding the certification and production of credence goods.

\section{Typical consumer}

Most of the literature on the certification of credence goods deals with a "typical consumer" who trusts the certification standards but finds any claims by the producer to be cheap talk.

I capture the consumer's trust in the certification standard by setting the mean of $f(Q)$, the probability density function that describes the consumer's perception of the likelihood that the good has some credence qualities, equal to the certification standard $(S)$ for any consumer who purchases a certified good. In other words, the consumer thinks the good most likely has the credence qualities defined by the standards. For a consumer of a non-certified good, the standard provides no guidance, so the mean of $f(Q)$ is independent of the certification standard. ${ }^{3}$

Figure 4 shows the zone of certification for a typical consumer. The graph on the left (Fig. 4a) represents the zone of certification when the consumer's ideal quality is equal to 1 (i.e., more credence qualities are always better). Certification in this case is optimal in most situations because it sends a useful signal to the consumer that the good has credence qualities that justify a higher price. The higher price, consequently, makes certification a profitable strategy for most producers of credence goods.

Non-certification is optimal, however, when the certification standard is near 0 . The reason is that certification in those situations does little to differentiate the quality of certified and non-certified goods. As a result, there is not enough of a difference in price between certified and non-certified goods to justify the extra costs of certification. This, in short, is the standard outcome.

The small area of non-certification in the upper-left corner of Fig. 4a is not often discussed in the literature and is the direct result of bringing the producer's motivation
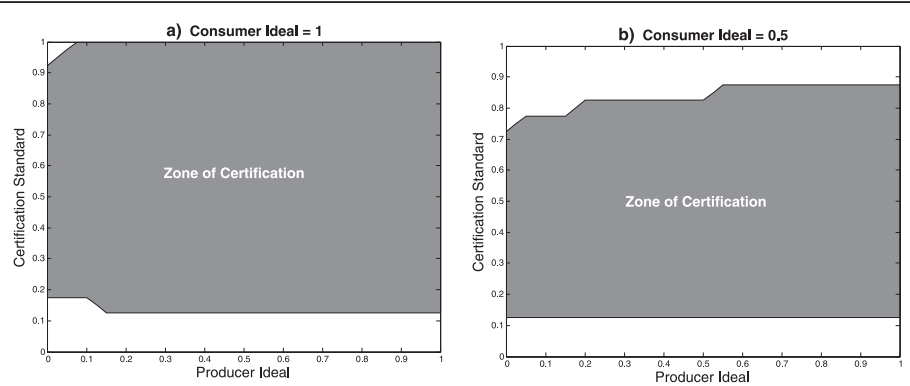

Fig. 4 The zone of certification for a "typical" consumer. a The zone of certification for a typical consumer whose ideal quality is equal to 1 (i.e., she prefers as many credence qualities as possible). $\mathbf{b}$ The zone of certification for a typical consumer whose ideal quality is equal to 0.5 
into the analysis. In this area, where the standard is high but the producer's ideal is low, certification would lead to a significant price differential and increased revenue. However, obtaining certification would force the producer to produce at a quality quite different from his ideal. When the difference is large enough, the negative effect on his motivation outweighs the benefit of a higher price.

I have been focusing on the relationship between the certification standard and the producer's ideal, but the graph on the right (Fig. $4 \mathrm{~b}$ ), which shows the zone when the consumer has an ideal quality equal to 0.5 , demonstrates that the consumer's ideal is also important. When the consumer's ideal quality falls, the top border of the zone of certification also falls. The reason is that the consumer's trust in the certification standard convinces her that when the standard is near 1, the good is likely to have many more credence qualities than the consumer prefers (the mean of $V(Q)$ is 0.5 ). This mismatch of beliefs and preferences reduces the consumer's willingness to pay for the good, decreases the certified price premium, and makes certification in the case of high standards less desirable for the producer.

\section{Skeptical consumer}

A skeptical consumer does not believe the producer's claims or believe in the reliability of the certification regime. Since neither the certification standard nor the producer's claims affect the consumer's belief about the good's credence qualities, the mean of $f(Q)$ is independent of both the certification standard $S$ and the producer's ideal $\hat{Q}$. This is not to say that certification is irrelevant. The Bayesian nature of the certified price means the consumer's willingness to pay for a certified good is still formed, in part, on the information certification provides (recall Eq. 2). Therefore, the price of a certified good is still likely to be higher than the price of a non-certified good although this price differential will be smaller than it would be with a typical consumer.

When faced with a skeptical consumer, it is optimal for the producer to seek certification only when the producer's ideal level of quality is similar to or greater than the certification standard (see Fig. 5a). There are several effects working in favor of the optimality of certification in that range. First, certified goods continue to offer a higher price, with the price premium increasing as the standard increases. When the consumer's ideal quality is lower (Fig. 5b), the price premiums
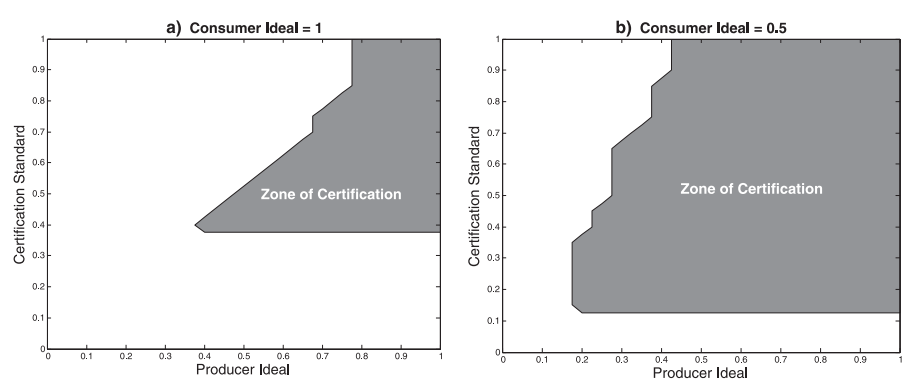

Fig. 5 The zone of certification for a "skeptical" consumer. a The zone of certification for a skeptical consumer whose ideal quality is equal to 1 (i.e., she prefers as many credence qualities as possible). $\mathbf{b}$ The zone of certification for a skeptical consumer whose ideal quality is equal to 0.5 
actually rise slightly because the consumer's low expectations are more in line with the consumer's lower ideals, and this causes the zone of certification to expand. Second, as we saw in the previous section, when the producer's ideals are higher than the certification standard, the standard does little to change the producer's choice of quality so producing a certifiable quantity also maximizes the motivational benefit. Finally, when the producer ends up producing a quality higher than that required by the standard, there will be fewer cover-up costs. All of these factors contribute to a large zone of certification to the right of the diagonal.

The opposite occurs when the certification standard is higher than the producer's ideals (the region above the diagonal). First, certification will induce the producer to increase quality beyond the ideal quality, reducing the motivation benefit. Second, the certified producer's production costs will be higher $\left(\gamma^{c}>\gamma^{n}\right)$. Finally, to avoid the higher production costs, the producer has a greater incentive to cheat (i.e., to seek certification with fewer credence qualities than the standard demands). This reduces the probability of being certified and increases cover-up costs. Together, these factors make certification much less desirable when the standard exceeds the producer's ideal.

\section{Trusting consumer}

In the last two cases, the consumer trusts the producer's claims about product quality. The first is the "trusting" consumer, who believes everything and is the opposite of the skeptical consumer. I model this sort of consumer as one who believes a certified good has a level of quality equal to the certification standards (the mean of $f(Q)$ is equal to $S$ ) and believes a non-certified good has a level of quality equal to the producer's ideal (the mean of $f(Q)$ is equal to $\hat{Q}$ ). This assumes the producer's ideal quality is somehow honestly revealed to the consumer.

Figure 6 shows the zone of certification for a trusting consumer. When, as in Fig. 6a, the consumer's ideal quality is 1 (i.e., the more credence qualities, the better), the bottom border of the zone of certification falls close to the diagonal, meaning certification is optimal when the certification standard exceeds the producer's ideal level of quality. This outcome makes sense when a consumer wants as many credence qualities as possible. When the certification standard is higher than the producer's standard, certified goods promise the consumer more credence
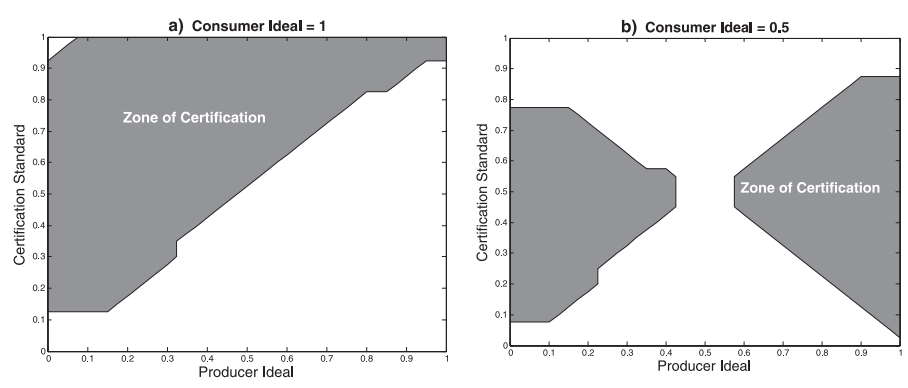

Fig. 6 The zone of certification for a "trusting" consumer. a The zone of certification for a trusting consumer whose ideal quality is equal to 1 (i.e., she prefers as many credence qualities as possible). $\mathbf{b}$ The zone of certification for a trusting consumer whose ideal quality is equal to 0.5 
qualities, making the good more valuable and increasing the certified price premium. When the producer promises more credence qualities, however, noncertified goods are more valuable to the consumer.

The effect of trust is vividly illustrated in Fig. 6b, the case where the consumer's ideal quality is 0.5 . Here, non-certification is optimal when the producer's ideal is near 0.5 , which roughly coincides with the consumer's ideal. Like Fig. 6a, the boundaries of the zone of certification are roughly determined by whether the producer's ideal or the certification standard more closely aligns with the consumer's ideal.

\section{Relationship-based consumer}

A relationship-based consumer also trusts the producer but has a distrust of the certification regime. I capture the beliefs of this last type of consumer by setting the mean of $f(Q)$ equal to the producer's ideal, regardless of whether the good is certified.

The most surprising thing about Fig. 7 is that a small zone of certification still exists. If a consumer believes the producer's claims about the good's credence qualities, why would the producer go through the expense of certification? One would expect certification to still result in a price premium due to the Bayesian nature of the consumer's willingness to pay, but the consumer's skepticism toward the certification regime should retard the price premium and the producer's declining motivation benefit should drive him away from seeking certification.

Nonetheless, there may be a range where producer ideals and certification standards roughly coincide that is favorable for certification (along the upper-right portion of the diagonal). When standards and producer ideals are similar, the quality produced by a certified producer will be similar, if not identical, to that of a non-certified producer. This implies that any difference in the motivation benefit between certified and noncertified producers will be small and production costs will be similar unless marginal costs were steeply increasing in quality. The marginal benefits, however, are likely to favor certification. A high producer ideal, backed up by high certification standards, will cause the price differential $\left(P^{c}-P^{n}\right)$ to grow and certification to become increasingly attractive. These advantages to certifying melt away, however, as the consumer's ideal level of quality falls (Fig. 7b).
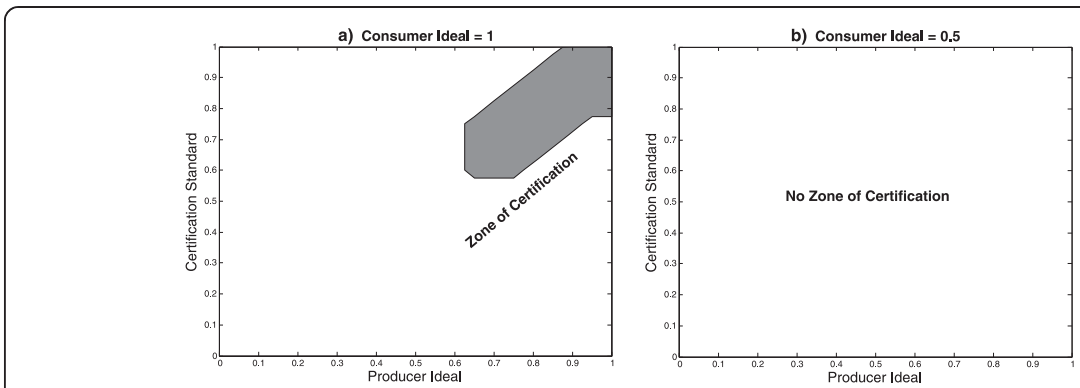

Fig. 7 The zone of certification for a "relationship-based" consumer. a The zone of certification for a relationship-based consumer whose ideal quality is equal to 1 (i.e., she prefers as many credence qualities as possible). $\mathbf{b}$ The zone of certification disappears for a relationship-based consumer whose ideal quality is equal to 0.5 


\section{Will certification-based regulation lead to more credence qualities?}

It is now possible to combine the results from the last two sections to determine whether a certification regime will induce producers to produce a good with more credence qualities.

As I demonstrated above, certification induces a producer to improve the quality of his good when the certification standards exceed the producer's ideal (the area on and above the diagonal). When the producer is selling to a typical or trusting consumer, both of whom rely on the certification standard to form their beliefs about the quality of the good, the zone of certification overlaps the area where certification tends to increase quality. In other words, the producers who seek certification will be induced to increase the quality of their goods.

However, when the consumer is skeptical or relationship-based, the zone of certification falls in the area where the certification standard is less than the producer's ideal (below the diagonal). In this case, a producer in the zone of certification is not likely to increase the quality of the good above the quality that would have been chosen without certification. Therefore, the consumer's skepticism about the certification standards leads to the self-fulfilling result of the certification regime doing little or nothing to increase the quality of the good produced.

\section{Changing the model parameters}

These general conclusions are not highly dependent on the model's parameters (described in Appendix 2), but the exact shape and size of the zone of certification is. It is useful, therefore, to change the parameters in the MATLAB simulation and examine the effects on the zone of certification.

One important parameter is the mean of $f(Q)$, which represents the expected level of quality the consumer attaches to the good in the absence of trust in the producer or the certification standard. The default value of the mean of $f(Q)$ was assumed to be 0.1 . However, when a certification standard or producer does not provide a consumer with useful information about a credence good, the consumer could form expectations about the good's quality in many different ways, such as a producer's reputation, word of mouth, or information from other "experts" like the retailer, and their expectations about the quality of the good could vary greatly. I found that when the mean of $f(Q)$ increases, the zone of certification shrinks. If the consumer already thinks the good has many credence qualities, certification will add little, if anything, to the consumer's willingness to pay. Consequently, the certified price premium falls and the zone of certification shrinks.

Another important parameter is the standard deviation of $f(Q)$, which can be interpreted as the consumer's confidence in her perception of quality. When this parameter increases (i.e., the consumer's confidence in her assessment of the good's quality falls), the zone of certification also increases. When a consumer is not confident in her assessment of quality, certification provides much useful information and certified goods become more valuable. As we have seen, a higher certified price premium makes certification optimal for the producer under a broader set of circumstances. 
Finally, certification costs $(\delta)$ also affect the size of the zone of certification. As certification costs increase, the bottom border of the zone of certification moves upward toward a higher standard. The reason is straightforward. As the certification standard increases, the price premium received from certifying also increases. As the certification costs go up, it takes a higher price premium to justify a producer seeking certification. Therefore, it is not worth paying higher certification costs when the certification standard is weak.

\section{Conclusions}

The degree to which a consumer trusts the producer of a credence good and the certification standard that governs it and the degree to which the producer is motivated to produce a good of a certain quality both have important effects on certification-based regulation. Certification will be widely sought by the producers of credence goods only when consumers trust the certification regime and do not trust the producer. In all other cases, there are likely to be a significant number of credence good producers who opt out of the certification process. Specifically, certification will be less likely when:

1) The certification standards do not align with the producer's ideal level of quality. When the certification standards are higher than the producer's ideal, certification would compel the producer to add credence qualities he would not otherwise have added. In many cases, this reduces the net benefit of certifying enough to outweigh the certified price premium. This result, and the one that follows, is similar to Roe and Sheldon (2007), although their conclusion was based on producers' need to obtain a second, more stringent, certification to assure consumers of their higher quality.

2) The certification standards do not align with the consumer's ideal level of quality. There is a similar effect when the certification standard is not consistent with the quality most desired by the consumer. In that case, certification tells a consumer that the good has a level of quality that will actually reduce the consumer's utility. This effect reduces the certified price premium and makes certification less desirable for the producer.

3) The consumer trusts the producer.

When the consumer trusts the producer, the certified price premium will be reduced and is more likely to be overwhelmed by the negative aspects of certification. This is especially true when the producer's quality claims are consistent with the consumer's preferences.

4) The consumer does not trust the certification standard.

When a consumer has little faith in the certification regime (e.g., does not trust the inspection or enforcement process), the certified price premium falls and the circumstances under which certification is optimal become more limited.

These results suggest several things to consider when regulating credence goods. First, since the zone of certification is so dependent on the circumstances, there may be opportunities to improve outcomes by tailoring certification standards to the context (e.g., different standards for grocery stores than farmers' markets). 
Second, the optimality of non-certification in many circumstances suggests mandatory certification would reduce overall welfare. In fact, in those instances where the consumer trusts the producer, mandatory certification could undermine that trust and inhibit the exchange of useful information. Finally, if regulators wish to increase the number of producers choosing to certify, weakening standards and making certification easier to obtain will not always lead to that result. Lower standards will often decrease the certified price premium and/or reduce the producer's motivation benefit, making certification the less desirable choice.

\section{Endnotes}

${ }^{1}$ While this paper often uses organic food as an example of a credence good facing the imperfect information problem, the concepts apply equally to the certification of most credence goods.

${ }^{2}$ This assumption is for analytical convenience. Allowing for the possibility of mistakenly failing to grant certification would not change the general results.

${ }^{3}$ The mean is assumed to be 0.1 for this analysis. In the following section, I will discuss how changes in the mean of $f(Q)$ affect the zone of certification.

\section{Appendix 1: Structure of the MATLAB code to finding the zone of certification}

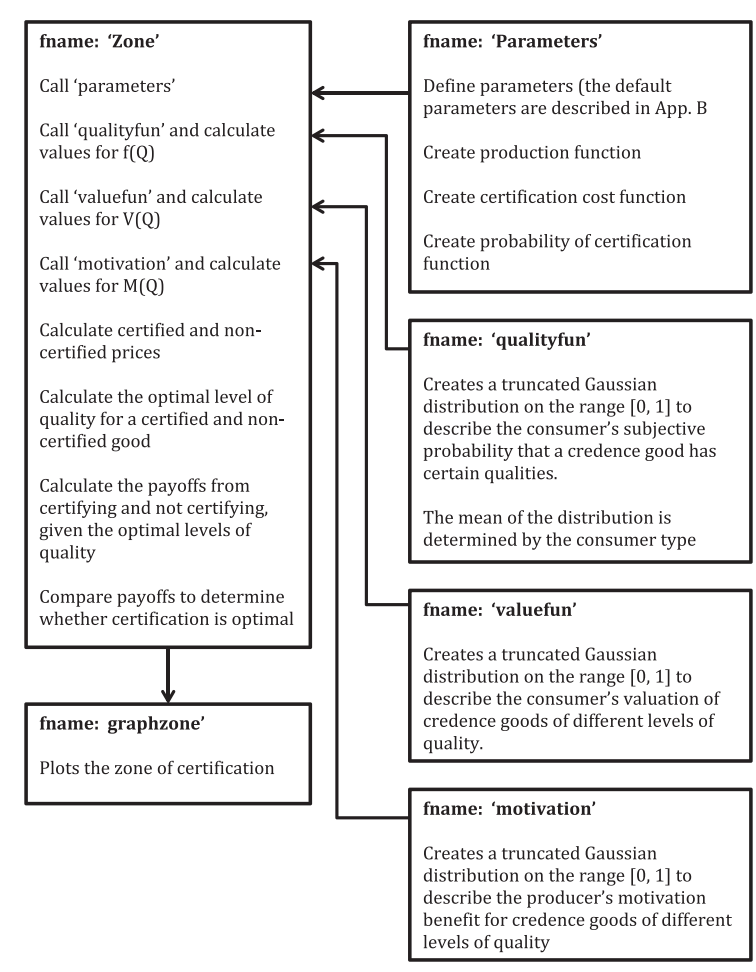

Fig. 8 The complete MATLAB code is available from the author upon request 


\section{Appendix 2: Default parameters for determining the zone of certification}

$f(Q)$

mean $=0.1$

standard deviation $=0.1$

$V(Q)$

mean $=0.5$ or 1 (see Figs. 4, 5, 6, and 7)

standard deviation $=0.2$

maximum value $=10$ (the price a consumer would pay for a credence good of quality equal to the mean)

$M(Q)$

mean $=$ determined by $\hat{Q}$, the horizontal axis of Figs. 4, 5, 6, and 7

standard deviation $=0.2$

maximum value $=10$

\section{Certification costs}

$\delta=0.1$ (when certification standards are met)

\section{Competing interests}

I have read Agricultural and Food Economics' policy on competing interests and declare that I have no competing interests related to this article.

\section{Acknowledgements}

None.

An earlier draft of this paper was presented at the 2015 Agricultural \& Applied Economics Association and Western Economics Association Annual Meeting, San Francisco, CA, July 26-28.

Received: 15 September 2015 Accepted: 23 June 2016

Published online: 29 June 2016

\section{References}

Akerlof G (1970) The market for lemons: quality uncertainty and the market mechanism. Q J Econ 84(3):488-500

Cáceres D (2005) Non-certified organic agriculture: an opportunity for resource-poor farmers? Outlook Agric 34(3):135-140

Caswell J, Mojduszka E (1996) Using informational labeling to influence the market for quality in food products. Am J Agric Econ 78:1248-1253

Caswell J, Padberg D (1992) Toward a more comprehensive theory of food labels. Am J Agric Econ 74:460-468

Constance D, Choi J, Lyke-Ho-Gland H (2008) Conventionalization, bifurcation, and quality of life: certified and non-certified organic farmers in Texas. South Rural Sociol 23:208-234

Darby M, Karni E (1973) Free competition and the optimal amount of fraud. J Law Econ 16:67-88

Deci EL (1971) Effects of externally mediated rewards on intrinsic motivation. J Pers Soc Psychol 18:105-115

Dulleck U, Kerschbamer R (2006) On doctors, mechanics, and computer specialists: the economics of credence goods. J Econ Lit 44(1):5-42

Emons W (1997) Credence goods and fraudulent experts. RAND J Econ 28(1):107-119

Frey B (1994) How intrinsic motivation is crowded out and crowded in. Ration Soc 6(3):334-352

Giannakas K (2002) Information asymmetries and consumption decisions in organic food product markets. Can J Agric Econ 50:35-50

Golan E, Kuchler F, Mitchell L (2001) Economics of food labeling, Economic Research Service, U.S. Dept. of Agriculture, Agriculture Economic Report No. 793

Guthman J (2001) Organic production in California: ideal and real, California Institute for Rural Studies

Hall A, Mogyorody V (2001) Organic farmers in Ontario: an examination of the conventionalization argument. Sociol Rural 41(4):399-422

Kallas Z, Serra T, Gil J (2009) Farmer's objectives as determinant factors of organic farming adoption. Agric Econ 41(5):409-423

McCluskey J (2000) A game theoretic approach to organic foods: an analysis of asymmetric information and policy. Agric Resour Econ Rev 29:1-9 
Munasib A, Jordan J (2011) The effect of social capital on the choice to use sustainable agricultural practices. J Agric Appl Econ 43(2):213-227

Roe B, Sheldon I (2007) Credence good labeling: the efficiency and distributional implications of several policy approaches. Am J Agric Econ 89(4):1020-1033

Ward R, Hunnicutt L, Keith J (2004) If you can't trust the farmer, who can you trust? The effect of certification types on purchases of organic produce. Int Food Agribusi Manag Rev 7(1):60-77

Submit your manuscript to a SpringerOpen ${ }^{\circ}$ journal and benefit from:

- Convenient online submission

- Rigorous peer review

- Immediate publication on acceptance

- Open access: articles freely available online

- High visibility within the field

- Retaining the copyright to your article

Submit your next manuscript at $\boldsymbol{\sim}$ springeropen.com 